\section{Wildlife disease can put conservation at risk}

SIR - In their Letter 'Global trends in emerging infectious diseases' (Nature 451, 990-993; 2008), Kate Jones and colleagues reveal that emerging human infectious diseases are becoming globally more prevalent, particularly those originating from wildlife. Even when cases of all other transmission types started to decrease during 1990-2000 compared with previous decades, cases of wildlife-associated human diseases continued their upward trend. The authors highlight the implications for conservation, advocating more monitoring and preservation of areas rich in biodiversity to counter it.

They do not mention the social and psychological effect this proliferation of wildlife-associated zoonoses could have. Such diseases are widely perceived as a threat to humans (see, for example, W. D. Newmark et al. Biol. Conserv. 63, 177-183; 1993). Negative interactions with wildlife tend to stifle support for conservation policies and initiatives. The increasing prevalence of such diseases could stand in the way of the very conservation initiatives that Jones and colleagues are recommending to protect human health.

Widespread disease in wildlife populations could encourage humans to view wild animals as pests, instead of as resources to be protected and enjoyed. Risk-perception research on wildlife-associated zoonoses would confirm the extent to which this shift has occurred. Such research would also identify gaps between the public's attitudes and epidemiological assessments, and would help to gauge the extent of public support for different proactive management plans. This would enable wildlife managers to decide which plans would be the most politically and socially viable, as well as the best ways to inform the public about them.

Darrick T. Evensen

Department of Natural Resources, Cornel University, Ithaca, New York 14853, USA

\section{Hall and Keynes join Arbor in the citation indexes}

SIR - The career of the non-existent author Ann Arbor is well-known to connoisseurs of computerized databases and citation indexes. Usually listed as the last author, she is sometimes credited with the academic degree "MI". Ann is not actually a person, but the city of Ann Arbor, Michigan, home of the University of Michigan. Her 'degree' is a misinterpretation of the abbreviation for Michigan: MI. She pre-dates online computerized databases, and was often listed in the paper edition of Index Medicus.
Ms Arbor now has a UK rival in the team of Walton Hall and Milton Keynes. Like her, they are usually listed as last authors. The online database Google Scholar lists them as co-authors of 46 publications, in addition to their solo work (see http://tinyurl.com/ 386wuo). Walton Hall is actually a building on the campus of the Open University in Milton Keynes. These 'authors' have a useful role to play: they can be used to check the accuracy of the databases and indexes. Daniel C. Postellon

Helen DeVos Children's Hospital, 230 Michigan NE, Grand Rapids, Michigan 49503, USA

\section{Growth of activism calls for more thoughtful solutions}

SIR - Animal-welfare extremism is spreading, as reported in your News story 'Animal-rights activists invade Europe' (Nature 451, 1034-1035; 2008). For example, activists blocked plans to build laboratory facilities in Venray, the Netherlands, using a campaign that included painting threats on the laboratory directors' houses.

Although many people are concerned about animal experimentation, most do not understand the rationale behind these illegal activities, which generate considerable fear in the research community. Researchers respond by wanting to reduce transparency and asking the government to increase repression of activists - following the UK example of stricter legislation.

Today's understanding of the motivation underlying both normal and abnormal behaviour indicates that this response could be counterproductive. A better solution would be to channel frustrations into more constructive activities. The extremists have received positive reinforcement from their success in blocking the Venray plans. Reduced transparency will only increase societal concern, and repression risks exporting the problem (as it did from the United Kingdom to the Netherlands). Worse, as the extremists are motivated by frustration, repression may amplify the problem.

More constructive solutions include the provision of some form of democratic control, and perceived justice, to people concerned about laboratory-animal welfare. Membership of animal-protection organizations and voting for animal-friendly parties have not proved adequate. As with farm-animal welfare, society could opt for alternative routes. For example, people could request information from medical charities on their funding of animal experiments (and see www.rds-online.org.uk). Medical treatments developed through animal experimentation could be labelled, in the way that some food products are labelled with information about animal welfare. Increased transparency and transfer of at least part of the responsibility from the researcher back to society are key to resolving the wider problem underlying animal extremism. Name and address supplied mrcbmb@gmail.com

Readers are welcome to comment at the Nautilus blog, http://tinyurl.com/2dks88.

\section{How genetic censorship would harm everyone}

SIR - In your Editorial 'Genetics benefits at risk' (Nature 451, 745-746; 2008), you indicate that the entire scientific and medical community adamantly supports the US Genetic Information Nondiscrimination Act, because it would protect people from discrimination by health insurers or employers on the basis of genetic information. I, for one, do not support this bill.

Better information allows better matching of people and jobs, and of people and insurance policies. The purpose of firms is to produce goods and services efficiently, and information helps to improve efficiency. The purpose of insurance is to manage risk, and information availability lowers risk.

You fear that the use of genetic information by employers and insurers will lead to social inequality - or, in other words, you trust that ignorance will preserve equity and fairness. There are better ways to deal with social inequality than to force ignorance upon workers, employers and insurers. And a better informed, more efficient, wealthier society creates better conditions for everyone to live decent and productive lives, whatever our genetic make-up.

Marcelino Fuentes

Facultade de Ciencias, Universidade da Coruña, E-15071 A Coruña, Spain

\section{Qualities of a lone author are beneficial to science}

SIR - Mott Greene's Essay 'The demise of the lone author' (Nature 450, 1165; 2007) highlights the proliferation of multipleauthor papers over the past century. Although collaborative efforts are essential and properly result in papers with many authors, I believe that funding agencies and institutions should also encourage single-author papers. The effort and initiative required to publish alone suggests an independent and tenacious scientist - both highly desirable qualities in any researcher. Kevin Hallock

Boston University School of Medicine, 650 Albany Street, Boston, Massachusetts 02118, USA 